\title{
Perspective
}

Susanne Rieger*, Dirk Bethe, Angela Bagorda, Dorothea Treiber, Jörg Beimler, Claudia Sommerer, Britta Höcker, Alexander Fichtner, Tobias Vinke, Martin Zeier, Georg Friedrich Hoffmann and Burkhard Tönshoff

\section{A need-adapted transition program after pediatric kidney transplantation}

https://doi.org/10.1515/jtm-2018-0004

Received May 9, 2018; accepted September 28, 2018

Abstract: A successful transition of renal transplant recipients from pediatric to adult care requires a structured, need-adapted and multidisciplinary approach to preserve renal graft function during this critical period of life. In this article we present our clinical protocol for transition from pediatric to adult care, which we developed on the basis of the International Society of Nephrology (ISN)/International Pediatric Nephrology Association (IPNA) consensus guidelines influenced by our own experience. This transition program was established in our center in July 2017. The entire transition process is structured and accompanied by a transition key worker (social worker). From 12 years of age we train pediatric renal transplant recipients in medical knowledge, self-management skills and networking with self-help groups. The training is adapted to the individual patient's intellectual ability, lasts about 10 years and takes place with increasing intensity. Repeatedly we perform standardized informational interviews and check patient's knowledge of transplantrelated topics. Psychosocial and educational issues are evaluated concomitantly. The actual transfer takes place in a pediatric-adult-transition clinic. Relevant medical and psychosocial aspects are discussed and the future treatment regimen is established. The date of transfer is adapted to the individual patient's need; it varies between 18 and 24 years of age. In periods of increased risk for nonadherence the transfer is postponed to intensify the efforts for training and assistance. After transfer a standardized

\footnotetext{
*Corresponding author: Dr. med. Susanne Rieger, Department of Pediatrics I, University Children's Hospital, Heidelberg, Germany, E-mail: Susanne.Rieger@med.uni-heidelberg.de Dirk Bethe, Angela Bagorda, Dorothea Treiber, Britta Höcker, Alexander Fichtner, Tobias Vinke, Georg Friedrich Hoffmann and Burkhard Tönshoff: Department of Pediatrics I, University Children's Hospital, Heidelberg, Germany

Jörg Beimler, Claudia Sommerer and Martin Zeier: Division of Nephrology, Department of Internal Medicine, University Hospital Heidelberg, Heidelberg, Germany
}

evaluation of each individual patient takes place focusing on medical and psychosocial issues and on satisfaction with the transition process. Collection of these data is still in progress and will be analyzed systematically at a later stage in order to evaluate the impact of this new transition program on the stability of transplant function. That analysis might serve as a basis for negotiations about refunding with health insurance companies.

Keywords: multidisciplinary approach; pediatric-adulttransition clinic; self-management skills; transition key worker.

Transition of pediatric renal transplant recipients to adult care is a highly relevant topic. Nowadays, $85 \%-90 \%$ of children with severe chronic kidney disease (CKD) survive into adulthood [1, 2]. Startling data about unexpected loss of transplants within 36 months after transfer in up to one third of patients [3] resulted in intense efforts to standardize and optimize transition. One reason for an unfavorable course after transfer is the generally increased risk of non-adherence of adolescents until the age of 25 years. This phenomenon is better understood since modern brain research and functional brain MRI imaging have shown that mental maturation continues into young adulthood. Especially the development of the prefrontal cortex, which is essential for executive functions such as action planning, lasts until the age of 24-25 years [4, 5]. In addition, the transfer from the familiar pediatric team and center to the unknown adult service is emotionally a big step for most patients. Furthermore, the pediatric team is felt to have more time for individualized and comprehensive care for patients and their families.

Given the importance of this topic the International Society of Nephrology (ISN) and the International Pediatric Nephrology Association (IPNA) worked out a consensus report, focusing on the training, personal responsibility and autonomy of each patient. They stress how important it is that the transition is adapted to the

Ә Open Access. (C) 2019 Susanne Rieger, Dirk Bethe, Angela Bagorda, Dorothea Treiber, Jörg Beimler, Claudia Sommerer, Britta Höcker, Alexander Fichtner, Tobias Vinke, Martin Zeier, Georg Friedrich Hoffmann and Burkhard Tönshoff, published by De Gruyter. (cc))BY Commons Attribution 4.0 Public License. 
individual patient's need and that both the professional team and the parents are supportive for the patient during this complex process [6]. Taking into account the major points of this consensus report we established our own transition program in our center. Since July 2017 we are training all pediatric renal transplant recipients according to this transition protocol and have transferred them accordingly since October 2017.

Involved professions are (i) the treating pediatric nephrologist, (ii) the transplant nurse, who mainly trains the patient in medical topics, but also encourages and trains personal responsibility, (iii) a psychologist who evaluates and assists with psychological health, school education and vocational training as well as treatment adherence, (iv) a social worker, who informs about topics and questions of social law, and - if needed (v) a hospital teacher. The entire process is structured and organized by the transition key worker (social worker by profession), who informs about the program and works through questionnaires with the patient. She also supports patients regarding school education and vocational training. The psychologist, the social worker and the transition key worker support the patient actively in getting access to self-help networks and in practical questions of life management. The program was introduced to the teams of pediatric and adult nephrologists in several presentations. This training was considered to be sufficient by the team members. In addition, every 3 months there is a structured meeting of all staff members involved in the transition process to exchange their experiences. Parents are trained in medical transplant-related knowledge from time of transplantation and also attend patient training until a patient age of approximately 16-18 years. Thereafter, patients are trained alone. In addition, parents are encouraged to support the increasing autonomy and responsibility for medical affairs of the adolescents.

General principles of the transition procedure are the following: The entire transition process lasts approximately 10 years. Taking into account the recommendations of ISN/IPNA consensus guidelines [6] and exemplary generic transition programs such as the British "Ready Steady Go" [7] we start the training already at the age of 12-14 years. This point in time seems reasonable as it coincides with the increasing desire for autonomy of teenagers. Furthermore, starting the transition process at an age of 12 years allows sufficient time for patient training at consultations and therefore takes out pressure of time. Autonomy, personal responsibility and medically relevant knowledge are trained with increasing intensity, adapted to the developmental stage and intellectual ability of the patient. The actual transfer to adult service can take place as soon as the patient is 18 years old and demands it himself. But usually we transfer at the age of 21-22 years, because published data indicate that a transfer age of 18 years is associated with a higher rate of non-adherence and adverse outcome than a transfer age of 21-22 years [3, 8]. We carefully take into account the following psychosocial and medical transfer requirements: (i) stability of the allograft and physical health in general, (ii) psychosocial stability and sufficient social support, (iii) completed school education, (iv) successful initiation of vocational training, (v) stable social surrounding, (vi) completed transition training and (vii) consensus with the patient family and the transplant team about the timing of transfer. Transfer has also to be reconciled with other involved medical specialties. During instable medical and/or psychosocial periods it is generally reasonable to postpone transfer in order to intensify the efforts for training and assistance.

The transition program is adapted to different age groups. Age group 12-14 years: It is introduced for the first time at the age of 12-14 years by the pediatric nephrologist. The teenagers are trained in the following medical topics: what is the underlying renal disease, date of transplantation, name, indication and dosage of medication, serum creatinine baseline values, target tacrolimus trough level etc. But also the personal responsibility is enforced, e.g. we encourage to fill the pill organizer, to assure adequate fluid intake, to measure blood pressure and body weight, independently but still supervised by the parents. A standardized informational interview rounded off by check of knowledge is conducted at least once in this age group.

Age group 15-17 years: The transition key worker contacts adolescent patients and their families for the first time at the age of 15-17 years and hands out the flyer with her contact data. She again presents our transition concept, its content and time schedule. A standardized questionnaire identifies the state of knowledge, autonomy and self-responsibility, the psychosocial situation and detects the degree of need of support (Table 1). If possible (not in case of patients with severe developmental delay) the outpatient visit is divided into two parts: The first part is done with the patient alone to train him/her in discussing medically relevant topics, but also to talk trustfully about confidential topics such as drugs, alcohol, sexuality and contraception. At the end of the visit the parents are invited to join and to discuss their concerns. The psychosocial and medical team evaluates adherence in an open, explorative interview. Furthermore, information about changes of social legislation after the 18th birthday is handed out, e.g. extra payment for medication, transport to the hospital, and professional secrecy towards 
Table 1: Questionnaire for the preparation of transfer from the center for child and adolescent medicine to adult care (modified according to refs. [9-15]).

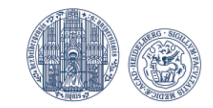

UNIVERSITÄTS

KLINIKUM

HEIDELBERG

Questionnaire to change from pediatrics and juvenile medicine to adult medicine

Dear(s)

You are currently under the care of a pediatrician. In some time you will have to change to adult medicine (transition). In preparation, we would like to ask you to fill out this questionnaire and discuss it with us during office hours. This questionnaire is made for people with very different diseases and therefore also contains questions that may not apply to your disease. In these cases, please tick the box "Does not matter for my illness".

First name and surname:

Date of birth:

Date:

\begin{tabular}{|c|c|c|c|c|}
\hline & Agree & $\begin{array}{l}\text { Agree } \\
\text { partly }\end{array}$ & $\begin{array}{l}\text { Not } \\
\text { true }\end{array}$ & $\begin{array}{l}\text { Does not } \\
\text { matter for } \\
\text { my illness }\end{array}$ \\
\hline \multicolumn{5}{|l|}{ A. Knowledge about the disease } \\
\hline 1. I know the name of my illness and I can explain it to others. & & & & \\
\hline 2. I know what investigations are being carried out and why. & & & & \\
\hline 3. I know what symptoms and complications can occur during the course of my illness. & & & & \\
\hline 4. I'm seeing signs of disease worsening. & & & & \\
\hline 5. I know the basics of the heredity of my disease. & & & & \\
\hline 6. I know the connection between my illness and sexuality and contraception. & & & & \\
\hline 7. I know the special effects of tobacco, alcohol and other drugs on my illness and its treatment. & & & & \\
\hline \multicolumn{5}{|l|}{ B. Therapy and treatment } \\
\hline 8. I know what my treatment involves. & & & & \\
\hline 9. I know the names of my medications. & & & & \\
\hline 10. I know the effects and side effects of my treatment/medication. & & & & \\
\hline 11. I take my medication on my own or carry out my treatment on my own. & & & & \\
\hline 12. I carry out my treatment regularly or take my medication regularly. & & & & \\
\hline 13. I can adapt my medication/treatment to special situations (stress, infections, leisure time). & & & & \\
\hline 14. I know what can affect the effect of my medication. & & & & \\
\hline 15. I have an emergency ID card and I always carry it with me. & & & & \\
\hline \multicolumn{5}{|l|}{ C. Support and information } \\
\hline 16. I receive sufficient support from my partner, my parents or other adult trusted third parties. & & & & \\
\hline $\begin{array}{l}\text { 17. In my environment (friends or family) there is an adult person who knows my illness and the } \\
\text { treatment well. }\end{array}$ & & & & \\
\hline 18. I feel sufficiently informed about support offers. & & & & \\
\hline 19. I know how to contact people with the same disease. & & & & \\
\hline 20. My illness and/or its treatment represents a financial burden for me. & & & & \\
\hline \multicolumn{5}{|l|}{ D. Plans for the future and the job } \\
\hline 21. I know what to consider when preparing my travels. & & & & \\
\hline $\begin{array}{l}\text { 22. I know what I have to consider with regard to my illness/treatment when obtaining a driving } \\
\text { licence and in road traffic. }\end{array}$ & & & & \\
\hline 23. I know what my teacher/employer needs to know about my illness. & & & & \\
\hline 24. I know the particularities of my illness, which I have to consider when choosing a career. & & & & \\
\hline $\begin{array}{l}\text { 25. I know what I need to bear in mind in the event of pregnancy and childbirth during my } \\
\text { illness/treatment. }\end{array}$ & & & & \\
\hline \multicolumn{5}{|l|}{ E. Hospital contacts } \\
\hline 26. I speak (also) alone with my doctor during consultation hours or look for an escort myself. & & & & \\
\hline 27. I can make my own doctor’s appointments. & & & & \\
\hline
\end{tabular}




\begin{tabular}{|c|c|c|c|c|}
\hline & Agree & $\begin{array}{l}\text { Agree } \\
\text { partly }\end{array}$ & $\begin{array}{l}\text { Not } \\
\text { true }\end{array}$ & $\begin{array}{l}\text { Does not } \\
\text { matter for } \\
\text { my illness }\end{array}$ \\
\hline 28. I know how to reach my practitioners (e.g. doctors, diet advice). & & & & \\
\hline 29. I can take care of follow-up prescriptions or prescriptions myself. & & & & \\
\hline \multicolumn{3}{|l|}{ F. I would like the treatment team... } & \multicolumn{2}{|c|}{$\begin{array}{l}\text { Please mark } \\
\text { with a cross }\end{array}$} \\
\hline \multicolumn{3}{|l|}{ More information about my illness. } & & \\
\hline \multicolumn{3}{|l|}{ Support with questions about school, training, studies and career. } & & \\
\hline \multicolumn{3}{|l|}{$\begin{array}{l}\text { Information about dealing with authorities and what changes in law (e.g. health insurance, } \\
\text { offices, insurances) when you reach the age of majority (18 years). }\end{array}$} & & \\
\hline IV. $\quad$ The organization of psychological counseling. & & & & \\
\hline
\end{tabular}

Comments/questions/wishes:

Thank you for your cooperation!

Table 2: Standardized informing interview for the 15-17 year olds (modified according to ref. $[9,16]$ ).

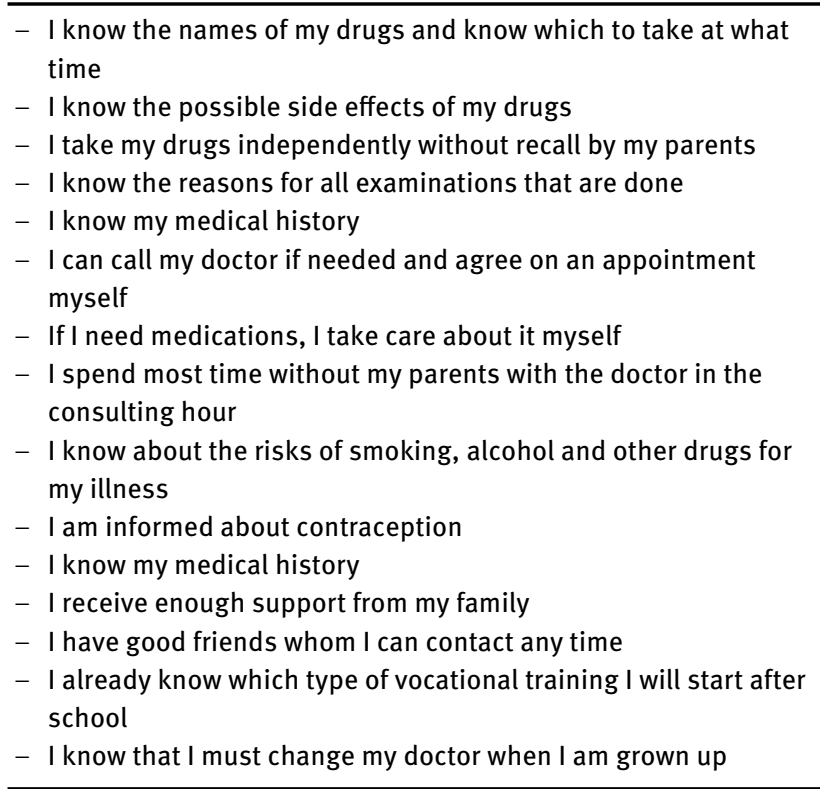

parents. The German "Finally-Adult-Program" funded by the "Kuratorium für Dialyse und Nierentransplantation" $(\mathrm{KfH})$ is explained and participation prepared, if desired. The standardized informational interview is conducted at least once a year by the transplant nurse, and - if needed by the pediatric nephrologist in charge. This interview for the 15-17 year olds is exemplarily presented in this report (Table 2). It was developed on the basis of a previously published checklist $[9,16]$ and slightly modified according to the needs of a renal transplant recipient.

At the age of 18 years the transition key worker contacts the patient again and presents the time schedule of transition. If needed another evaluation of the current status of the vocational training as well as counseling about social rights is performed. Visits to the transplantation after-care clinic take place initially without parents, though they can join the visit in the end. The medical informative interview is performed every 3 months (at least every 6 months) by the transplant nurse, if needed by the covering physician. It is documented in the electronic patient chart. This medical checklist for the $\geq 18$ year old patients (Table 3) was developed by our medical team using the Delphi procedure.

As outlined above, most adolescent renal transplant recipients are not ready for transition at an age of 18 years. Therefore the age group of 19-20 years represents the effective phase of transition, i.e. most patients will be transferred within the two following years. Once per quarter the respective patients are discussed in the multidisciplinary team including the transition key worker. The medical informative interview is performed every 3 months by the physician in charge or the transplant nurse. Usually it is necessary to reevaluate the vocational training and to re-inform about legal and social rights by the psychosocial team, including the transition key worker. If needed practical support is given, e.g. liaising with employment agencies. The entire process is documented in a separate part of the electronic patient chart.

Transfer from the pediatric to the adult service within our transplant center takes place in a joint pediatric-adult transition clinic. The pediatric nephrologist in charge passes all essential medical and psychosocial information orally as well as in written comprehensive form to the adult nephrologist in charge. This also includes relevant medical topics of other specialties involved in the patient's care such as nutritional or urological aspects. In addition, a short check list with the most important topics is 
Table 3: Medical checklist for adolescents $\geq 18$ year-old.

\begin{tabular}{|c|c|c|c|c|}
\hline Questions & $\begin{array}{l}\text { Date of } \\
\text { check }\end{array}$ & $\begin{array}{l}\text { Date of } \\
\text { check }\end{array}$ & $\begin{array}{l}\text { Date of } \\
\text { check }\end{array}$ & $\begin{array}{l}\text { Date of } \\
\text { check }\end{array}$ \\
\hline \multicolumn{5}{|l|}{ You know which medications you take and its dosages? } \\
\hline \multicolumn{5}{|l|}{ You know your medications and you can arrange them? } \\
\hline \multicolumn{5}{|l|}{ You take your medications autonomously and you have a "recall system" (e.g. mobile phone)? } \\
\hline \multicolumn{5}{|l|}{ What is the name of your immunosuppressive drugs? } \\
\hline \multicolumn{5}{|l|}{ What are the target trough levels of your immunosuppressive drugs? } \\
\hline \multicolumn{5}{|l|}{ For which indication you take which drug? } \\
\hline \multicolumn{5}{|l|}{ Which blood values must you particularly pay attention to? } \\
\hline \multicolumn{5}{|l|}{ What is the baseline of your serum creatinine? } \\
\hline \multicolumn{5}{|l|}{ At what leukocyte count you have to call your nephrologist? } \\
\hline \multicolumn{5}{|l|}{ What to do if your general practitioner prescribes you a new drug? } \\
\hline \multicolumn{5}{|l|}{ Whom you have to contact in case of medical problems? } \\
\hline \multicolumn{5}{|l|}{ What is a good level of your blood pressure and when do you have to call your nephrologist? } \\
\hline \multicolumn{5}{|l|}{ What is your daily amount of fluid intake? } \\
\hline \multicolumn{5}{|l|}{ What you are not allowed to eat or drink? } \\
\hline \multicolumn{5}{|l|}{ What to do if you are sick? } \\
\hline \multicolumn{5}{|l|}{ What to do in case of diarrhea? } \\
\hline \multicolumn{5}{|c|}{$\begin{array}{l}\text { In case of diarrhea: when you need to have your blood checked and to which values you have to } \\
\text { pay particularly attention to? }\end{array}$} \\
\hline \multicolumn{5}{|c|}{ What to do in case of vomiting? } \\
\hline \multicolumn{5}{|l|}{ What to do in case of dysuria? } \\
\hline \multicolumn{5}{|l|}{ What to do if you have forgotten to take your medication? } \\
\hline \multicolumn{5}{|l|}{ What to do if you took your drugs by mistake twice? } \\
\hline \multicolumn{5}{|l|}{ What to do in case of herpes? } \\
\hline \multicolumn{5}{|l|}{ What to do in case of fever and coughing? } \\
\hline What kind of sun protection do you apply and which clinical controls are necessary? & & & & \\
\hline
\end{tabular}

compiled, e.g. stability of the allograft, relevant comorbidities, adherence, psychosocial background, and the job situation. Thereafter the patient gets to know his new adult nephrologist and is informed how the adult service works and how to get in contact, if help is needed. Together the future treatment regimen, the frequency and location of after-care check-ups and the date for the next visit in the outpatient clinic are established. If desired by the patient the next visit takes place again in the joint pediatric-adult transition clinic. In the meantime, the patient is invited to contact the adult nephrologist for any problems, but also to get in contact with the familiar pediatric team if he/she feels more comfortable with that. After this first visit at the adult service the transition key worker continues to offer support, e.g. how to organize the next aftercare appointment. Nevertheless, from this point on the responsibility for the medical treatment is transmitted from the pediatric nephrologist to the adult nephrologist.

Follow-up: 6 weeks, 3 months and 6 months after the transfer the patient receives a standardized questionnaire about physical health, the psychosocial situation and satisfaction with the entire transition process. A formal requirement for this is a written informed consent by the patient. These questionnaire-based interviews are performed by the transition key worker and supported by the covering pediatric nephrologist when necessary.

An algorithm for transition for different age groups is given in Table 4.

\section{Discussion}

Successful transition of adolescent renal transplant recipients to adult care is of utmost importance for the individual patient's health prognosis. The prevention of premature graft loss by a successfully executed transition is also an important contribution to transplantation medicine in general, because each prematurely lost organ in a young patient aggravates the organ shortage. Last not least, successful transition is cost-effective, because it reduces transplant-related morbidity and the risk of returning to chronic dialysis therapy $[17,18]$. Publications on the unfavorable course and loss of renal transplants after transfer without a comprehensive transition process [3] stress the significance of a structured transition program including patient teaching and empowerment. Furthermore, the actual date when the adolescent is transferred 
Table 4: Algorithm for transition for different age groups.

12-14 years
- Introduction to
our transition
program
- Start of training in
medical
knowledge in a
basic, easy way,
adapted to the
individual mental
capacity

18 years
- Again presentation
of the transition
program by the
transition key
worker
- Same offers as for
the 16 years old
- Training in medical
knowledge at least
every 6 month

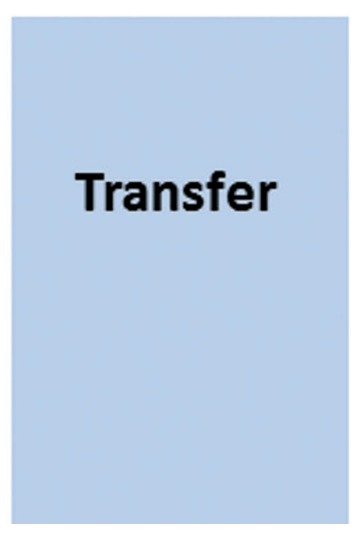

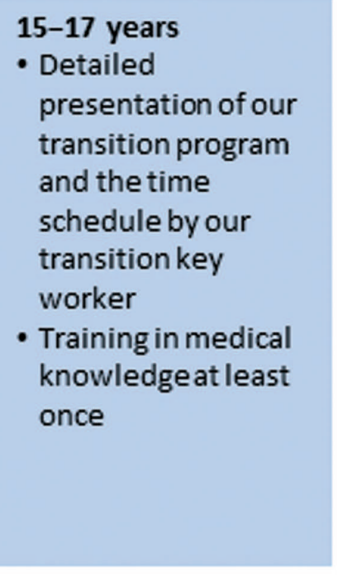

\section{9-20 years} Intensive phase of transition

- Training in medical knowledgeevery 3 month

- Discussion with the multidisciplinary team every 3 month

- Intensified support by psychologists social and transition key worker

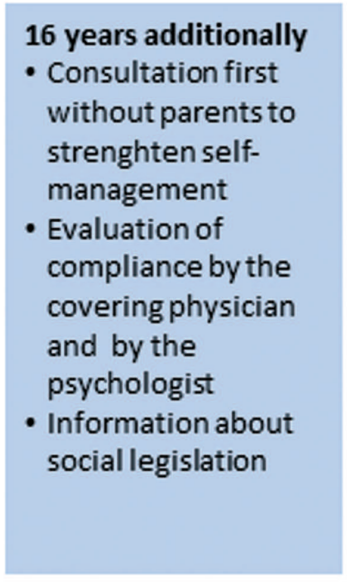

21-22 years
- Concrete schedule
for transfer
- Medical epicrisis
- Concrete support by
transition key
worker for transfer
- Continuing training
of medical
knowledgeevery 3
month and
discussion in the
multidisciplinary
team

6 weeks, 3 months, 6 months after transfer:

- Questionnaire about health, psychosocial well-being, satisfaction with the transition process to the adult service should depend on individual criteria rather than on chronological age, because transplant losses peak in 18-21-year-old patients [8] and a transition after this critical period appears therefore advisable in most patients. Both the transition process per se and the vulnerable period of adolescence are critical for the prognosis of the transplant.

The current policy to favor children and adolescents in the allocation of renal allografts [19] is justified by many facts [20]. But it also has to be accompanied 
by great efforts to reduce any risk of premature loss of renal transplant function due to non-adherence on the one hand, but also due to insufficient support during the transition process on the other hand. Policy realizes and supports the rights of patients with chronic diseases on the highest accessible level of health [https: //www.behindertenrechtskonvention.info/in-kraft-tretender-konvention-3138]. While there is often good medical care for children and adolescents with chronic diseases available, comparable structures of medical care beyond childhood are scarce. Taking these points into account many efforts were recently undertaken to improve the transition process $[6,16,21]$. In Northern Germany for example, a transition program originally developed at a hospital in Berlin ("Berliner Transitionsprogramm") has been successfully established in several parts of the country; it also allows the reimbursement for the invested manpower and working time by health insurance companies. The implementation of this program in Central and Southern Germany is still pending.

We therefore established our own risk-adapted interdisciplinary transition program based on the ISN-IPNAconsensus guidelines and adjusted to the special features of the clinics for pediatric and adolescent renal transplant recipients in Heidelberg. We chose the ISNIPNA-consensus guidelines as the basis for our program, because these are particularly designed for patients with chronic kidney diseases (CKD) with the inherent risk of progression to end-stage renal disease. This group of CKD patients differs from other patient groups, for which the "Berliner Transitionsprogramm" was established, because they might lose their allograft and might need a retransplantation in the future. The group of pediatric renal transplant recipients has to struggle with the dramatic shortage of organs in addition to the burden of a chronic disease. For transplanted patients, a lack of continuous medical care is particularly disastrous, because of the highly increased risk of losing the organ in such a period [3]. We therefore feel that the complexity and medical severity of pediatric renal transplant recipients require a more intensive and prolonged transition program than the standard "Berliner Transitionsprogramm", which was primarily designed for less complex diseases such as diabetes mellitus and epilepsy.

Another generic transition program called "Ready Steady Go" has been successfully established for long-term chronic diseases in the UK [7]. Our transition program is comparable to "Ready Steady Go" regarding the following features: (i) Clear structure regarding content and temporal sequence, but adaptable to individual patient's needs; (ii) the early start of transition at the age of approximately 12 years in our program compared to $11+$ years in "Ready Steady Go"; (iii) use of a structured questionnaire to assess the stage of knowledge and autonomy and the need for further training and support. Our program differs from "Ready Steady Go" regarding the following aspects: (i) The higher flexibility of the actual age of transfer to adult care. In contrast to "Ready Steady Go" we do not have to transfer at the age of 18 years, but can postpone this until the age of approximately 22 years, when the patient himself and his caregivers feel that he is "ready to go". (ii) Our transition program has some generic aspects such as the structured questionnaire and the combined transfer clinic of pediatric and adult organ specialists, but our program is more focused on the special needs of this particular patient population including comprehensive and repetitive training of transplant-related knowledge. (iii) The presence of the familiar pediatric transplant nephrologist in the combined transfer clinic, (iv) the patient is assigned to one experienced adult transplant nephrologists, if possible. Therefore the continuity of medical care is preserved. Inspired by "Ready Steady Go" we plan to include "Ask 3 questions" [http://www.advancingqualityalliance.nhs. uk/SDM] in our skill training. These questions will help the patient to make medical decisions which suit best to his individual situation.

So far, we have transferred four patients to the adult service according to this protocol, and our current experience stress the urgent need for an intensified training before transfer and also for supporting the adolescents after transfer, particularly if support from their respective family is weak. Oral feedback from our patients about satisfaction with the entire transition process is encouraging. We are currently analyzing the performance of this transition program systematically, but the available data are too limited for a meaningful analysis. The impact of this new transition program on the stability of graft function will be assessed by comparing the number of patients with a loss of estimated glomerular filtration rate (eGFR) $\geq 50 \%$ within 2 years after transfer with historical data of matched controls before July 10/2017. In the medium term, this analysis will hopefully create a basis for reimbursement negotiations with health insurance companies to ensure the sustainability of this crucial transition program.

\section{Author Statement}

Research funding: Authors state no funding involved. Conflict of interest: Authors state no conflict of interest. 
Informed consent: Not applicable.

Ethical approval: Not applicable.

\section{References}

1. Lewis MA, Shaw J, Sinha M, Adalat S, Hussain F, Inward C. Demography of the UK pediatric renal replacement therapy population. UK Renal Registry Report. Bristol, UK: UK Renal Registry, 2008:Chapter 13, 257-67.

2. Ferris ME, Gipson DS, Kimmel PL, Eggers PW. Trends in treatment and outcomes of survival and adolescents initiating end-stage renal disease care in the United States of America. Pediatr Nephrol 2006;21:1020-6.

3. Watson AR. Non-compliance and transfer from pediatric to adult transplant unit. Pediatr Nephrol 2000;14: 469-72.

4. Durston S, Casey BJ. What have we learned about cognitive development from neuroimaging? Neuropsychologia 2005;44:2149-57.

5. Giedd JN. The teen brain: insights from neuroimaging. J Adoles Health 2008;42:335-43.

6. Watson AR, Harden PN, Ferris ME, Kerr PG, Mahan JD, Ramzy MF, et al. Transition from pediatric to adult renal services: a consensus statement by the International Society of Nephrology (ISN) and the International Pediatric Nephrology Association (IPNA). Kidney Int 2011;80:704-7.

7. Nagra A, McGinnity P, Davis N, Salmon A. Implementing transition: Ready Steady Go. Arch Dis Child Educ Pract Ed 2015;100:313-20.

8. Foster BJ, Dahhou M, Zhang X, Platt RW, Samuel SM, Hanley JA. Association between age and graft failure rates in young kidney transplant recipients. Transplantation 2011;92: 1237-43.

9. Keller K-M. Transition bei Jugendlichen mit CED. Monatszeitschrift Kinderheilkunde 2010;158:738-44.

10. Müther S, Müller B, Moers A von, Burger W. Berliner Transitionsprogramm - ein Strukturkonzept für die Transition in die Erwachsenenmedizin. In: Reincke M, Zepp F (Hrsg) Medizinische Versorgung in der Transition. Reihe Report
Versorgungsforschung, Bd 5. Deutscher Ärzteverlag, Köln, 2012.

11. Minden K, Schalm S. Arbeitskreis Transition der Deutschen Gesellschaft für Rheumatologie e.V., Fragebogen für die Jugendsprechstunde. https://gkjr.de/fuer-mitglieder/ informationen-fuer-mitglieder/transitionsunterlagen/.

12. The Royal Children's Hospital Melbourne: http://www.rch.org. $\mathrm{au} /$ transition/factsheets_and_tools/transition_checklists/.

13. Southampton Children's Hospital, Transition to adult care: Ready Steady Go: http://www.uhs.nhs.uk/OurServices/ Childhealth/TransitiontoadultcareReadySteadyGo/ Transitiontoadultcare.aspx.

14. The Hospital for Sick Children (Sickkids), Toronto: Good2Go Transition program: http://www.sickkids.ca/Good2Go/ForYouth-and-Families/Transition-Tools/Readiness-Checklists/ Index.html.

15. Findorff, J, Müther, S, von Moers, A, Nolting, H-D, Burger, W. Das Berliner Transitionsprogramm. Berlin, Boston: De Gruyter, 2016.

16. North American Society for Pediatric Gastroenterology, Hepatology and Nutrition (NASPGHAN): http://www.naspghan. org/files/documents/pdfs/medical-resources/ibd/Checklist_ PatientandHealthcareProdiver_TransitionfromPedtoAdult.pdf

17. Haller M, Gutjahr G, Kramar R, Harnoncourt F, Oberbauer R. Cost-effectiveness analysis of renal replacement therapy in Austria. NDT 2011;26:2988-95.

18. Villa G, Rodriguez-Carmona A, Fernández-Ortiz L, Cuervo J, Rebollo P, Otero A, et al. Cost analysis of the Spanish renal replacement therapy programme. Nephrol Dial Transplant 2011;26:3709-14.

19. Tönshoff B, de Boer J, Rahmel A, Heemann U. Änderungen der Allokation in der pädiatrischen Nierentransplantation bei Eurotransplant. Transplantationsmedizin 2011;23:40-9.

20. Tönshoff B. Allokation von Nierentransplantaten Neuregelung für pädiatrische Patienten. Nephrologe 2010;5(Suppl 1): 36-44.

21. American Academy of Pediatrics, American Academy of Family Physicians, American College of Physicians, Transitions Clinical Report Authoring Group, Cooley WC, Sagerman PJ. Supporting the health care transition from adolescence to adulthood in the medical home. Pediatrics. 2011;128:182-200. 